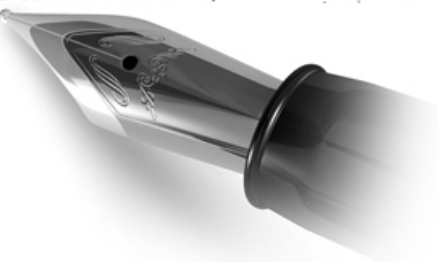
\title{
Editorial
}

\section{Is radioimmunotherapy a 'magic bullet'?}

\author{
Sung-Hyun Kim, M.D., Ph.D. \\ Division of Hematology-Oncology, Department of Internal Medicine, Dong-A University College of Medicine, Busan, Korea
}

Radioimmunotherapy (RIT) uses monoclonal antibodies directed against specific tumor antigens that are labeled with a particle-emitting radioisotope to deliver radiation directly to tumors (Fig. 1). Lymphoma is a good model for elucidating the effect of RIT because more than $90 \%$ of lymphoma B-cells express the cell-surface antigen CD-20. The 2 therapeutic agents for the management of lymphoma currently approved by the United States Food and Drug Administration (FDA) are ${ }^{90} \mathrm{Y}$ ibritumomab tiuxetan and

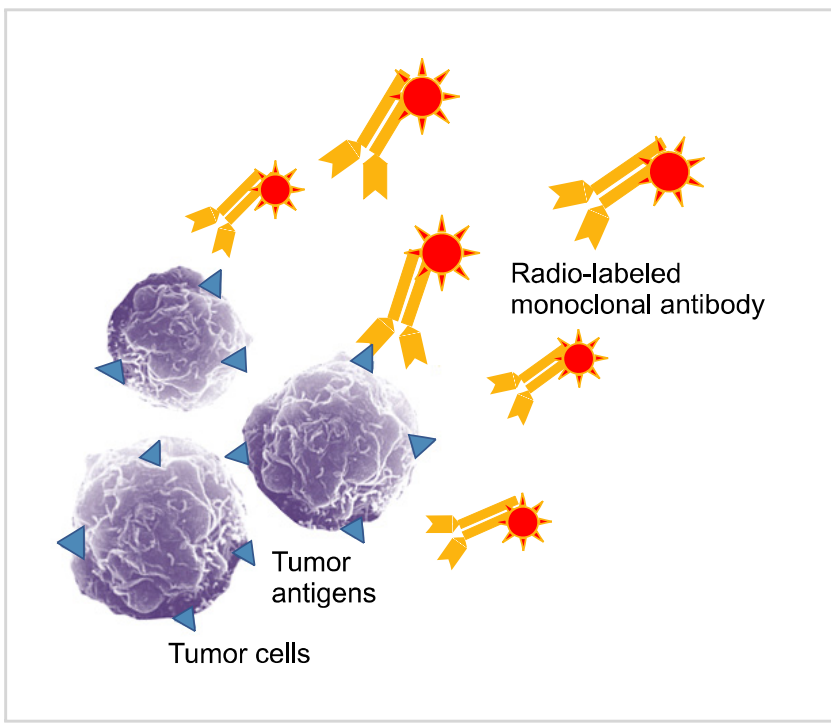

Fig. 1. Radioimmunotherapy (RIT) using monoclonal antibodies labeled with a radioisotope emitting gamma- or beta- rays.
${ }^{131}$ I tositumomab. FDA-labeled indications for RIT are the treatment of relapsed or refractory CD20+ follicular B-cell non-Hodgkin's lymphoma (NHL) and consolidation therapy in patients with follicular NHL who have shown a partial or complete response to first-line chemotherapy [1].

High-dose chemotherapy (HDC) conditioning administered in association with autologous stem cell transplantation (ASCT) or reduced-intensity conditioning with allogeneic stem cell transplantation are established treatment approaches for patients with chemotherapy-sensitive, relapsed, aggressive, or low-grade NHL. These approaches have been shown to be the only curative options for patients with relapsed NHL. Despite significant advances in ASCT, relapses occur in many patients receiving HDC in conjunction with ASCT because of contaminated grafts or cancer cells remaining in the patient after ablative chemotherapy. The role of RIT in conditioning therapy with stem cell transplantation for NHL is not yet established [2].

The current issue of the Korean Journal of Hematology includes a comparative study of this controversial issue. Jo et al. report that the use of ibritumomab tiuxetan in combination with busulfan, cyclophosphamide, and etoposide $(\mathrm{BuCyE})$ as a conditioning regimen elicited similar hematologic side effects and was associated with a potential benefit in efficacy when compared to treatment with BuCyE alone [3]. Although this study was not designed to evaluate the effect of the conditioning regimen on patient survival, the findings of this study indicate shorter event-free survival and overall survival than those reported by previous studies

This is an Open Access article distributed under the terms of the Creative Commons Attribution Non-Commercial License (http://creativecommons.org/licenses/by-nc/3.0) which permits unrestricted non-commercial use, distribution, and reproduction in any medium, provided the original work is properly cited. 
conducted in Western countries. As the authors point out, most patients in this study had heavily pretreated aggressive lymphomas, and poorer risk factors, which may have contributed to these results. Han et al. previously reported that tandem consolidation therapy using ${ }^{90} \mathrm{Y}$ ibritumomab tiuxetan followed by HDC with ASCT was not feasible for the treatment of high-risk patients with diffuse large B-cell lymphoma in remission after treatment with rituximab, cyclophosphamide, doxorubicin, vincristine, and prednisone (R-CHOP), because of poor efficacy [4].

Further studies are needed to determine whether ethnic differences in tumor biology affect survival. Well-designed randomized controlled trials for evaluating RIT as a conditioning regimen are also warranted. This study could have important implications for Korean medicine and may suggest that RIT can be safely adopted as a conditioning regimen for malignant lymphomas.

\section{REFERENCES}

1. Chamarthy MR, Williams SC, Moadel RM. Radioimmunotherapy of non-Hodgkin's lymphoma: from the 'magic bullets' to 'radioactive magic bullets'. Yale J Biol Med 2011;84:391-407.

2. Gisselbrecht C, Vose J, Nademanee A, Gianni AM, Nagler A. Radioimmunotherapy for stem cell transplantation in nonHodgkin's lymphoma: in pursuit of a complete response. Oncologist 2009;14(Suppl 2):41-51.

3. Jo JC, Yoon DH, Kim S, et al. Yttrium-90 ibritumomab tiuxetan plus busulfan, cyclophosphamide, and etoposide (BuCyE) versus $\mathrm{BuCyE}$ alone as a conditioning regimen for non-Hodgkin lymphoma. Korean J Hematol 2012;47:120-6.

4. Han EJ, Lee SE, Kim SH, et al. Clinical outcomes of post-remission therapy using (90)yttrium ibritumomab tiuxetan $\left(Z_{\text {Zevalin }}{ }^{\circledR}\right)$ for high-risk patients with diffuse large B-cell lymphoma. Ann Hematol 2011;90:1075-82. 